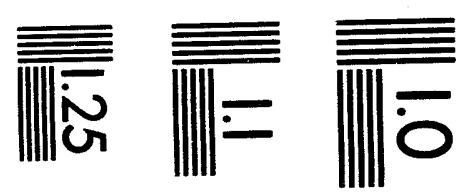

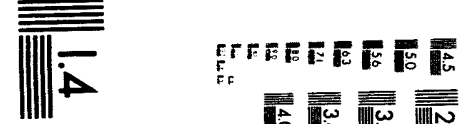

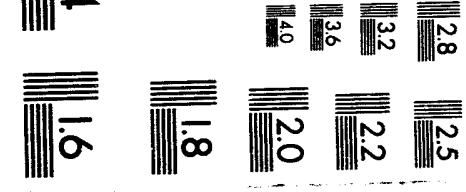



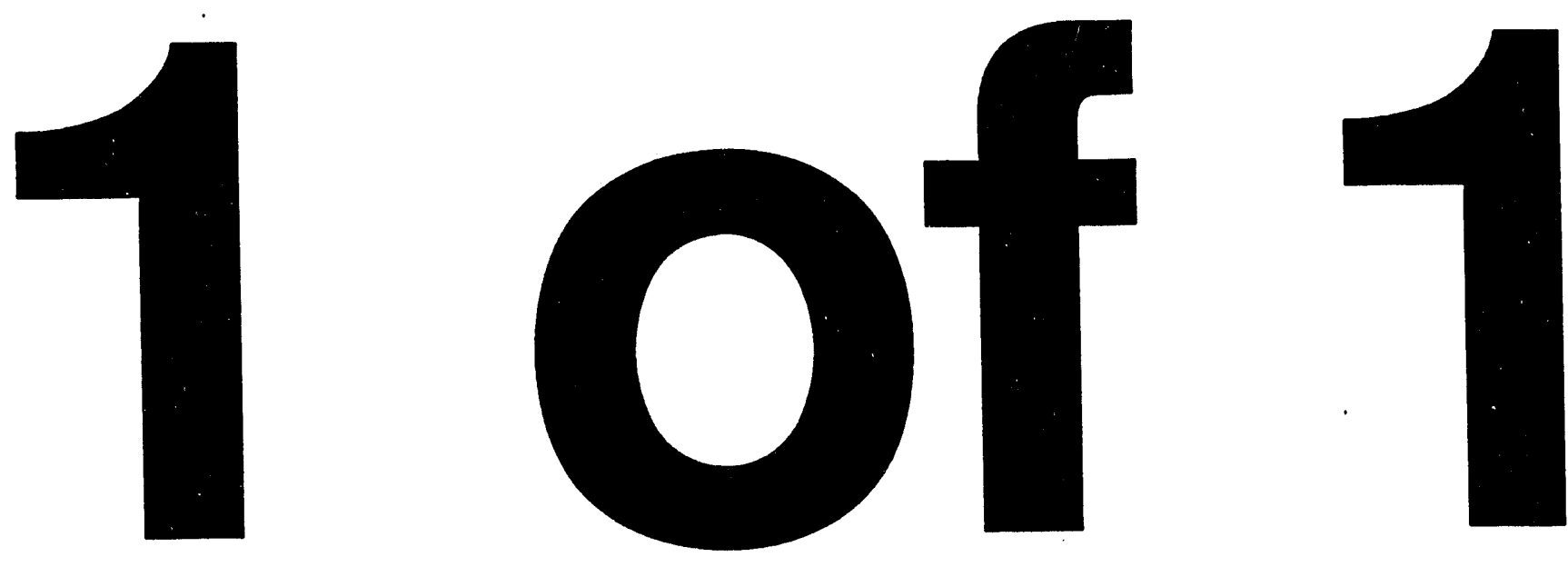


\title{
INDEPENDENT ASSESSMENT OF MELCOR AS A SEVERE ACCIDENT THERMAL-HYDRAULIC/SOURCE TERM ANALYSIS TOOL ${ }^{1}$
}

\author{
I. K. Madni \\ Department of Advanced Technology, Brookhaven National Laboratory \\ Upton, NY 11973, USA \\ F. Eltawila \\ Accident Evaluation Branch, U.S. Nuclear Regulatory Commission \\ Washington, DC 20555, USA
}

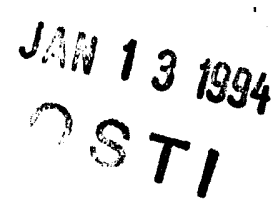

\begin{abstract}
MELCOR is a fully integrated computer code that models all phases of the progression of severe accidents in light water reactor nuclear power plants, and is being developed for the U.S. Nuclear Regulatory Commission (NRC) by Sandia National Laboratories (SNL). Brookhaven National Laboratory (BNL) has a program with the NRC called "MELCOR Verification, Benchmarking, and Applications," whose aim is to provide independent assessment of MELCOR as a severe accident thermal-hydraulic/source term analysis tool. The scope of this program is to perform quality control verification on all released versions of MELCOR, to benchmark MELCOR against more mechanistic codes and experimental data from severe fuel damage tests, and to evaluate the ability of MELCOR to simulate long-term severe accident transients in commercial LWRs, by applying the code to model both BWRs and PWRs. Under this program, BNL provided input to the NRCsponsored MELCOR Peer Review, and is currently contributing to the MELCOR Cooperative Assessment Program (MCAP). This paper presents a summary of MELCOR assessment efforts at BNL and their contribution to NRC goals with respect to MELCOR.
\end{abstract}

\section{INTRODUCTION}

MELCOR is a fully integrated computer code that models all phases of the progression of severe accidents in light water reactor nuclear power plants [Summers, 1991]. It is being developed for the NRC by SNL. BNL has a program with the NRC called "MELCOR Verification, Benchmarking, and Applications," whose aim is to provide independent assessment of MELCOR as a severe accident thermal-hydraulic/source term analysis tool. The scope of this program is to perform quality control verification on all released versions of MELCOR, to benchmark MELCOR against more mechanistic codes and experimental data from severe fuel damage tests, and to evaluate the sbility of MELCOR to simulate long-term severe accident transients in commercial LWRs, by applying the code to model both BWRs and PWRs. This paper presents a summary of MELCOR assessment efforts at BNL and their contribution to NRC goals with respect to MELCOR [USNRC, 1992], which includes:

1. MELCOR verification over the past several years during which all released versions of the code were installed on BNL's computer system, verification exercises were performed, and defect investigation reports were sent to SNL;

2. MELCOR analyses of integral severe fuel damage tests PBF SFD 1-1, SFD 1-4, FLHT-2, FLHT-4, and FLHT-5, and comparisons with experimental data and other calculations[Madni, 1989, 1991b, 1992, 1991c, 1993d, 1993e];

3. fully integrated applications calculations with MELCOR to simulate dominant accident sequences in Peach Bottom, a General Electric BWR with Mark I containment [Madni, 1990, 1993g] Oconee, a Babcock \& Wilcox PWR with large dry containment [Madni, 1991d, 1993a] ZION, a Westinghouse PWR with large dry containment, and Calvert Cliffs, a Combustion Engineering PWR [Madni, 1993b];

4. limited sensitivity studies which explore the impact of varying user input modeling and timestep control parameters on the calculated results for integral tests and full plant calculations; and

5. support to the NRC-sponsored MELCOR Peer Review Committee [Boyack, 1992] and MCAP.

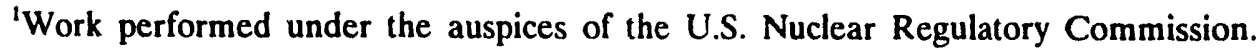


Over the past few years, all released versions of MELCOR have been installed and maintained on BNL's computer - systems, the latest released version at BNL being version 1.8.2. While BNL's main emphasis has been on VAX, the IBM 3090 mainframe computer and IBM RISC 6000 workstation have also been used. As part of verification, BNL has submitted several defect investigation reports to SNL, which have served to identify code errors and deficiencies, and have recommended improvements.

\section{BENCHMARKING}

In accordance with a study on experimental data alternatives for benchmarking MELCOR [Madni, 1988], which identified in-vessel phenomenology as an area in MELCOR that needed to be assessed, benchmarking analyses with MELCOR have been carried out for five integral severe fuel damage tests, as mentioned above.

A typical MELCOR nodalization for the test simulations is shown in Figure 1 [Madni, 1992]. There are 4 control volumes (inlet, fuel bundle, plenum, and environment) and 3 flow paths inte connecting them. The environment is a contrived volume and is assumed very large, allowing the system pressure to stay nominally constant, as in the experiments. The fuel bundle active length is nodalized into several axial segments and 1 radial ring. The shroud is nodalized axially to match the core cells and radially into several layers. Note that for FLHT5 , the test bundle was modeled as a BWR geometry, to allow the mass of zircaloy in the shroud liner and carriers to participate in oxidation with steam as a canister component.

The benchmarking calculations of integral severe fuel damage tests have helped to identify areas of modeling strengths and weaknesses in MELCOR; the most appropriate choices for input parameters; selection of axial nodalization for core cells and heat structures; and workarounds that extend the capabilities of MELCOR. These insights are explored in greater detail, with the help of selected results and comparisons from all five integral tests, as follows.

\section{Temperature Comparisons}

Comparisons between predicted and measured clad temperatures for all five tests are shown in Figures 2 to 6 . The agreement between MELCOR and the test data appears to be very good in the heatup phase, prior to the onset of accelerated oxidation of zircaloy.

For the first four tests (Figures 2 to 5), MELCOR generally fails to achieve measured the steep temperature rise prior to thermocouple failure. This could be attributed to several causes. Firstly, following clad rupture, the inner clad surface also gets exposed to steam and hence subject to oxidation. This is

not modeled in MELCOR. The effect may not be pronounced for steam-starved conditions, but there could nonetheless be local availability of steam close to the

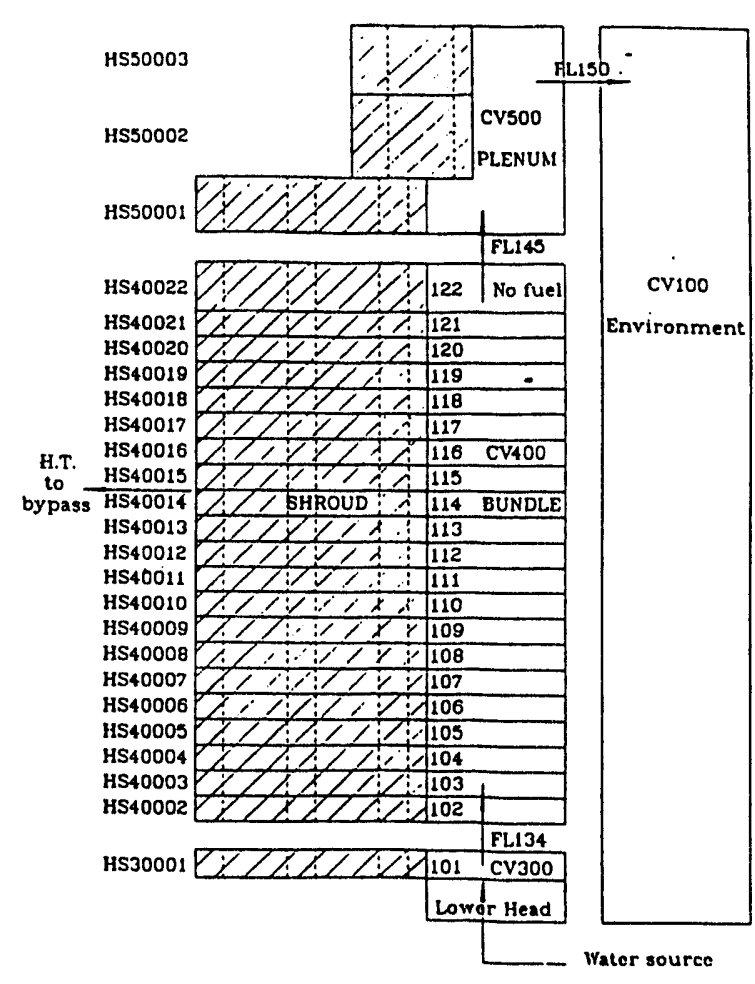

Figure 1. MELCOR Nodalization for the FLHT-2 Test

rupture opening. Secondly, the effect of clad ballooning (not modeled in MELCOR) could give rise to local flow reductions and temperature excursions. Finally, zircaloy present in the shroud inner liner, which can react with steam, was not allowed to oxidize in MELCOR as it was not a core component. This effect is not important for steam-starved conditions as in SFD 1-1. But where there is adequate steam supply, this may create divergence in predictions. For FLHT-5, the shroud liner was modeled as a canister of a BWR fuel bundle, and MELCOR predictions of both heatup and temperature escalation are very close to the measured values (see Figure 6). The sudden drop of MELCOR calculated cladding temperature in the figures represents clad melting and relocation downwards. SCDAP calculations show temperatures rising to almost $3000 \mathrm{~K}$ before dropping. This is because the $\mathrm{ZrO}_{2}$ holdup temperature in SCDAP was artificially specified to be $3000 \mathrm{~K}$, in order to minimize the predicted relocation, and increase the predicted hydrogen produced.

The difference between measured and predicted temperatures of the saddle, located outside the $\mathrm{ZrO}_{2}$ insulation layer, is more significant and can be attributed in part to the difficulty in estimating the effective thermal conductivity of the shroud during the high temperature transient.

The overall temperature behavior is strongly influenced by the calculated liquid level in the bundle region, and the converse is also true. A contributing factor to uncertainties in liquid level calculations is that the actual bundle flow was never constant, whereas MELCOR input (for convenience) assumed it to be constant. 


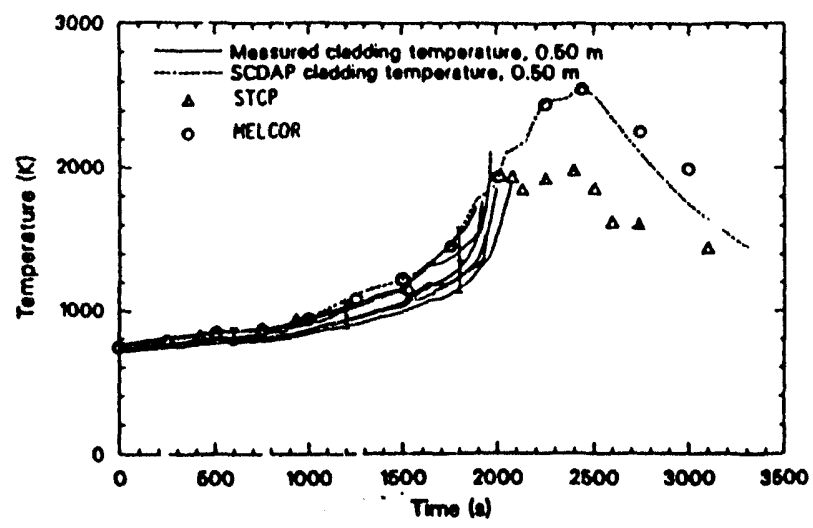

Figure 2. Comparison of measured and calculated clad temperatures, SFD1-1

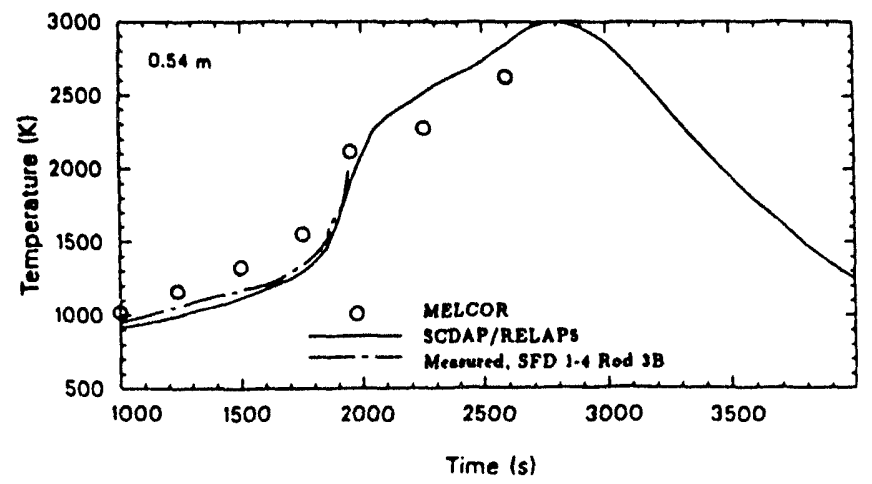

Figure 3. Comparison of measured and calculated clad temperatures, SFD1-4

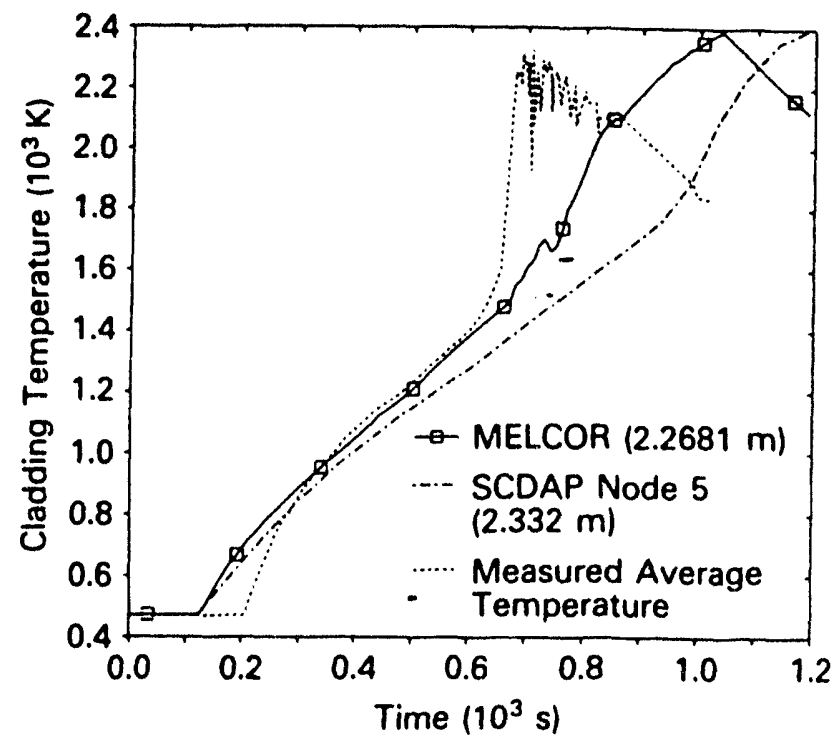

Figure 4. Comparison between calculated and measured temperatures, FLHT-2

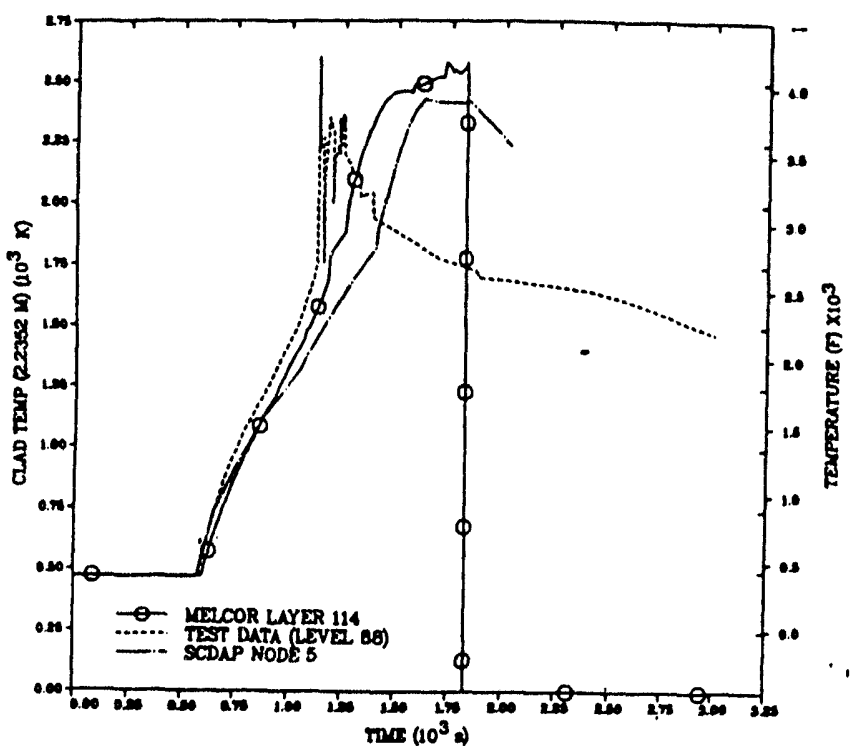

Figure 5. Comparison of calculated clad temperature with test data, FLHT-4

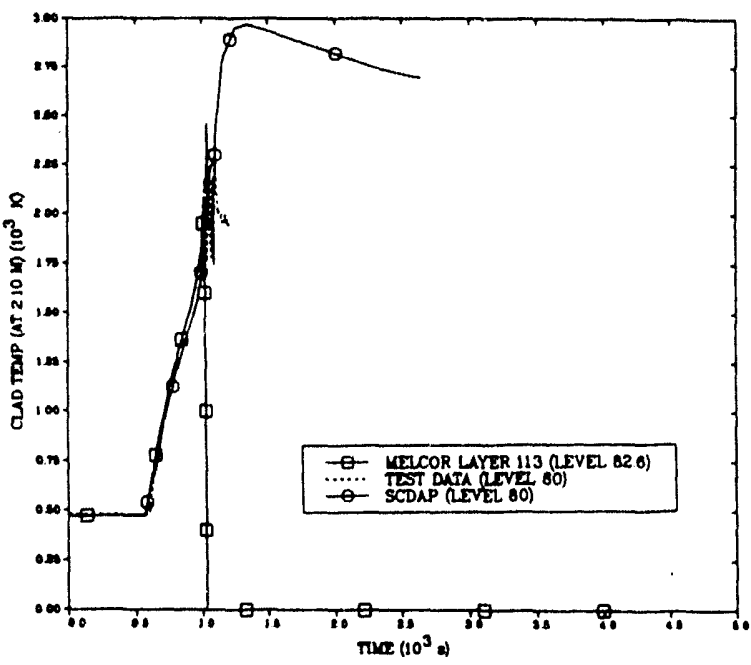

Figure 6. Measured and calculated clad temperatures, FLHT-5

\section{Oxidation and Hydrogen Production}

MELCOR calculates oxidation of both zircaloy and steel by solid-state diffusion through the oxide layer using standard parabolic kinetics, with appropriate rate constant expressions, and limited by steam availability. For zircaloy, the rate constant is evaluated from the correlation by Urbanic and Heidrick. The shift to rapid oxidation is modeled to occur at $1853 \mathrm{~K}$. This temperature can be changed via sensitivity coefficient, and was changed to $1700 \mathrm{~K}$ based on experimental observations for FLHT-4 and FLHT-5.

Table 1 shows comparisons between experimental and calculated values of total hydrogen production for all five integral experiments. MELCOR calculations show good agreement with test data for PBF SFD1-1, SFD1-4, and FLHT-2, and poor agreement for FLHT-4 and FLHT- 
5. The poor agreement for the FLHT-4 test could be attributed to the following: (i) There was less zircaloy mass available for oxidation in MELCOR, since the liner, being a heat structure, was not allowed to oxidize; (ii) MELCOR does not model clad ballooning, and allows no oxidation on the inside of the clad after it fails, and (iii) MELCOR calculates more relocation than in the test, bringing zircaloy to cooler regions of the bundle, where oxidation is suppressed. For FLHT-5, the predictions were improved by including the shroud liner as a canister component that could participate in oxidation. But the overprediction of relocation by MELCOR included significant relocation of the liner material, so that much less zircaloy from the liner was able to oxidize, as compared to the experiment. The better predictions for SFD1-1 and FLHT-2 tests can be partially attributed to less severe conditions in the tests resulting in almost no relocation, both observed and calculated. For SFD1-4, with a shorter length fuel bundle, and more severe conditions, there was significant relocation and the formation of blockages both calculated and observed in the test.

\section{Changes in Bundle Geometry}

The first indication of bundle geometry changes is clad ballooning. There is no explicit model for clad ballooning in MELCOR. Clad rupture is modeled to occur when the clad temperature at an axial cell exceeds a user-specified threshold temperature. This temperature has a default value of $1173 \mathrm{~K}$.

Table 2 [Madni, 1989] shows comparisons of measured (SFD 1-1) clad rupture times and location and MELCOR, SCDAP, and STCP predictions.

Based on this comparison, the default value of $1173 \mathrm{~K}$, while not mechanistic, is adequate and need not be changed unless appropriate data is available for a given application.

For SFD1-4, MELCOR calculates 40 percent of fuel relocated during the transient [Madni, 1991b]. This is a strong function of the assumed holdup temperature for the oxide shell in MELCOR (2600K in this case). An assumed holdup temperature of $2650 \mathrm{~K}$ resulted in almost no relocation. The value of $2600 \mathrm{~K}$ was selected based on observations of the SFD tests [Osetek, 1987]. This sensitivity to user-input quantities clearly demonstrates the need for the user to be knowledgeable about the modeled phenomena.

During the FLHT-4 test, much of the fuel bundle metal components including the liner above $1.5 \mathrm{~m}$ elevation was molten, but there was no indication of substantial relocation to lower bundle regions. In contrast, MELCOR calculated severe material relocation. Figures 7 and 8 [Madni, 1993d] shown the $\mathrm{UO}_{2}$ and zircaloy mass relocated, respectively, as calculated by MELCOR. The severe material relocation calculated by MELCOR could also be one of the reasons for the lower hydrogen production. For FLHT-5, MELCOR calculated severe material relocation, area reduction, and also a period of $250 \mathrm{sec}$ during which there was complete flow area blockage. The relocation caused early termination of oxidation, hence lower cumulative hydrogen produced. This deficiency also plagued the SCDAP code predictions of the test, in spite of artificially specifying a hold-up temperature of $3000 \mathrm{~K}$ to minimize downward relocation of material.

\section{Fission Product Release from Fuel}

The release of fission products from fuel is modeled in MELCOR using either the original CORSOR or CORSOR-M formulation. Depending on user choice, these release rates can be modified to be a function of the surface-to-volume ratio $(\mathrm{S} / \mathrm{V})$ of the material compared to the ratio in the CORSOR experiments. Both models are based on the same experimental data using irradiated fuel. It can be expected, therefore, that agreement with data for fresh fuel will be poor and much better for irradiated fuel. This was confirmed by comparisons of MELCOR calculations using CORSOR and data for test SFD 1-1 which used fresh fuel and test SFD 1-4 that used irradiated fuel. These are shown in Table 3. In FLHT-2, there were no measurements of fission product release. For FLHT-4, MELCOR (1.8.1) somewhat overpredicts and SCDAP somewhat underpredicts the noble gas release. For FLHT-5, there is a large band of uncertainty in the measurements of noble gas release, with a best estimate of -0.50. MELCOR (1.8.2) calculations using CORSOR are closer to the best-estimate values from the experiment than SCDAP.

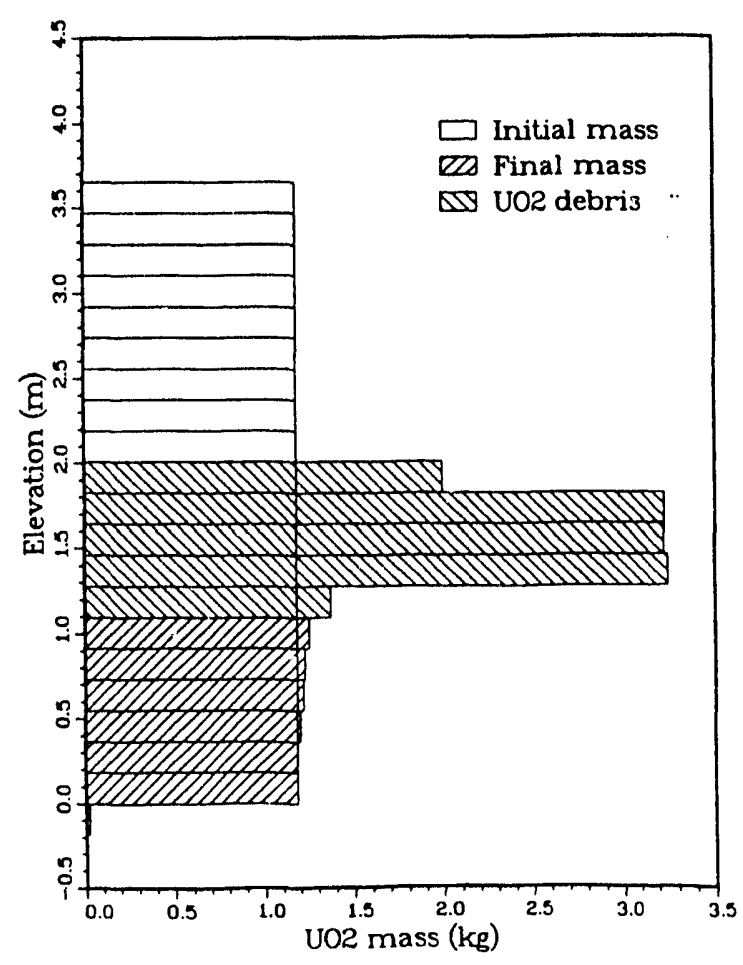

Figure 7. Fuel mass relocation calculated by MELCOR, FLHT-4 
Table 1. Comparison of Calculated Total Hydrogen and Test Data

\begin{tabular}{|c|c|c|c|c||}
\hline & \multicolumn{4}{|c|}{ HYDROGEN PRODUCED (g) } \\
\cline { 2 - 5 } & Experiment & MELCOR & $\begin{array}{c}\text { SCDAP or } \\
\text { SCDAP/RELAP5 }\end{array}$ & STCP \\
\hline PBF SFD 1-1 & $64 \pm 7$ & 67 & 89 & 60 \\
\hline PBF SFD 1-4 & $86 \pm 12$ & 86 & 87 & $\cdots$ \\
\hline FLHT-2 & $42 \pm 2.5$ & 43 & 39.7 & $\cdots$ \\
\hline FLHT-4 & $175-240$ & 119 & $110 / 125$ & $\cdots$ \\
\hline FLHT-5 & $220-340$ & 158 & 168 & - \\
\hline
\end{tabular}

Table 2. Comparison of Calculated Clad Rupture and Test Data for PBF SFD Test 1-1

\begin{tabular}{|c|c|c|c|}
\hline & Criterion & Rupture Time(s) & Axial Location (m) \\
\hline Experiment & & $1538-1632$ & $0.30-0.69$ \\
\hline MELCOR & $\mathrm{T}_{\text {tail }}=1173 \mathrm{~K}$ & 1370 & $0.46-0.57$ \\
\hline SCDAP & Mechanistic & 1290 & $0.46-0.55$ \\
\hline STCP & $\mathrm{T}_{\text {tail }}=1173 \mathrm{~K}$ & 1755 & \\
\hline
\end{tabular}

Table 3. Comparison of Measured and Calculated Release Fractions of Fission Products

\begin{tabular}{|c|c|c|c|}
\hline Element & Experiment SFD 1-1 & MELCOR (CORSOR) & SCDAP \\
\hline $\mathrm{Xe}, \mathrm{Kr}$ & $0.06 \pm 0.03$ & 0.53 & 0.04 \\
\hline $\mathbf{I}$ & $0.12 \pm 0.02$ & 0.53 & \\
\hline Cs & $0.094 \pm 0.014$ & 0.53 & \\
\hline Element & Experiment SFD 1-4 & MELCOR (CORSOR) & FASTGRASS \\
\hline Noble Gas & $0.23-0.52$ & 0.57 & 0.63 \\
\hline $\mathbf{I}$ & $0.24 \pm 19 \%$ & 0.57 & \\
\hline Cs & $0.51 \pm 15 \%$ & 0.57 & \\
\hline $\mathrm{Te}$ & 0.03 & 0.03 & \\
\hline Element & Experiment FLHT-4 & MELCOR (CORSOR) & SCDAP \\
\hline Noble Gas & $0.25 \cdot 0.55$ & 0.67 & 0.12 \\
\hline Element & Experiment FLHT-5 & MELCOR (CORSOR) & SCDAP \\
\hline Noble Gas & Best estimate $\sim 0.50$ & 0.53 & 0.20 \\
\hline
\end{tabular}




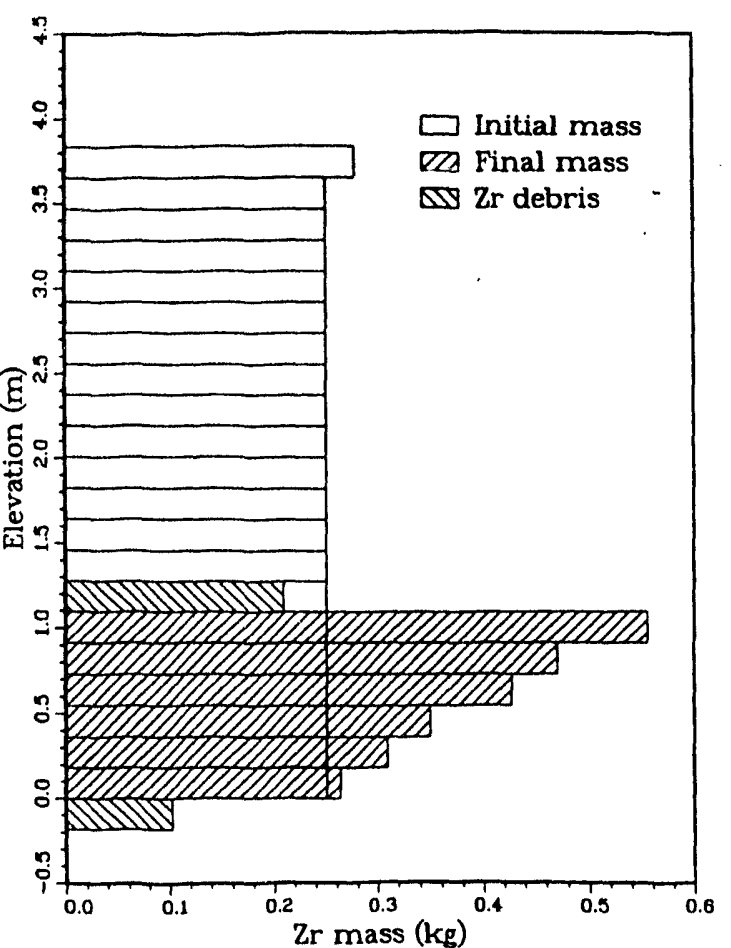

Figure 8. Zircaloy mass relocation calculated by MELCOR, FLHT-4

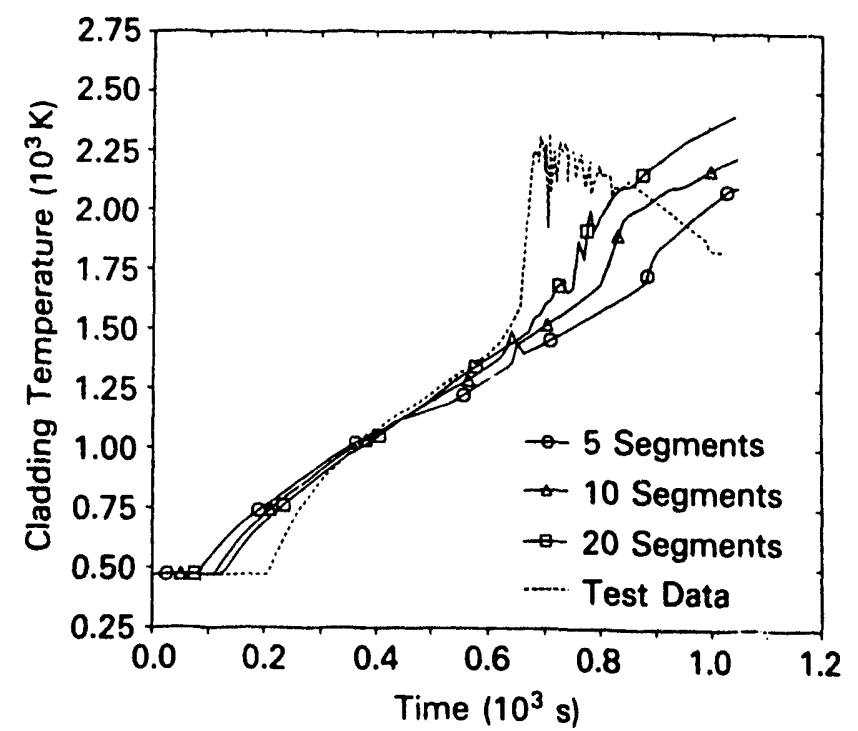

Figure 9. Impact of bundle nodalization on calculated clad temperatures, FLHT-2

\section{Effect of Axial Nodalization}

In the MELCOR core model, the bundle region is divided into concentric radial rings and axial segments that define core cells. Each cell may contain one or more components such as fuel pellets, cladding, etc.; and a lumped parameter approach is used for each component within a cell. For the FLHT-2 test simulation, besides the reference case with 20 axial segments in the bundle active region, three sensitivity cases with 5,10 , and 30 segments were also calculated. Comparisons of cladding temperatures are shown in Figure 9. Predicted values for hydrogen produced were $41 \mathrm{~g}$ (20 segments), $27 \mathrm{~g}$ (10 segments), and $26 \mathrm{~g}$ (5 segments), compared to the measured value of $42 \mathrm{~g}$. The case with 20 segments appears to give predictions that are closer to experimental data, compared with the coarser nodalizations. The calculations with 30 segments gave results that were very close to the 20 segments case and are not shown here. Hence, the choice of 20 axial segments in the active length was justified for the reference case, and was retained for all subsequent test simulations.

\section{Workarounds}

Experience with the code has allowed the use of several innovative inputs or "workarounds" that were successful in extending the capabilities of MELCOR [Madni, 1991a]. Most of them were used during MELCOR benchmarking analyses. For example, one can sometimes speed up a calculation if a problem control volume is eliminated without loss of physics. Initially, the MELCOR input model for the PBF SFD 1-1 test had a bypass volume, which received heat from the bundle region via the insulating shroud. During MELCOR simulation of the test, the timestep was severely restricted by Courant stability limitations. This problem was traced to the bypass volume which had very high flow through it. To improve timestep behavior, the bypass volume was replaced by a user-specified heat transfer coefficient $\left(\mathrm{H}_{\mathrm{em}}\right)$ on the outer surface of the shroud. The value of $\mathrm{H}_{\mathrm{ax}}$ was selected based on actually calculated values of $\mathrm{H}_{\text {ext }}$ from the code. Sensitivity calculations showed the results to be insensitive to this parameter over a substantial range $(5,000-15,000$ $\left.\mathrm{W} / \mathrm{m}^{2}-\mathrm{K}\right)$. That was expected, since the insulating shroud constitutes the largest resistance to heat transfer. This workaround increased the calculational $\Delta t$ by more than a factor of 50. A similar effect was also achieved in integral plant calculations by eliminating unimportant control volumes.

Another more recent workaround was to model the FLHT-5 test train as a BWR geometry, which allowed the mass of zircaloy in the shroud inner liner, carriers, and clad of one unfueled rod, to be modeled as a canister component and hence participate in oxidation with steam, as in the experiment. This was a modeling change from earlier simulations which treated the test train as a PWR geometry, in which the liner, being treated as a heat structure, could not participate in oxidation. The impact of this modeling change was to increase predicted cumulative hydrogen production by about $55-60 \%$.

\section{APPLICATIONS}

The applications effort at BNL has helped in maturing of the code, by evaluating the ability of MELCOR to successfully simulate various accident sequences and calculate source terms to the environment from both BWRs and PWRs. While the different applications did lead MELCOR into uncharted territory where new code errors were uncovered, the code has shown overall robustness in calculating sequences to 
completion. A few selected results from MELCOR simulation of a LOCA sequence in Oconee, a B\&W PWR

v with large dry containment are shown to provide a flavor for the applications aspect.

\section{Timing of Key Events}

Table 4 compares MELCOR (1.8DN) and STCP. predicted timing of key events for a LOCA sequence (3inch hot leg break) in Oconee [Madni, 1993a].

MELCOR predicts melting and relocation of core material to start somewhat earlier than STCP, but the relocation is more gradual. MELCOR calculations assume vessel failure to occur when temperature of the penetrations reached $1273.15 \mathrm{~K}$ (default value). The STCP calculation, on the other hand, assumes that gross failure of the lower head due to ablation would be the governing mode, based on depressurized conditions in the reactor vessel, and calculates vessel failure to occur much later. Thereafter, MELCOR calculates gradual release of core materials into the cavity, so that even after vessel failure in all 3 rings, there is a substantial amount of fuel still left in the core, whereas STCP essentially releases the entire core inventory at the time of vessel failure. This results in a less vigorous core-concrete interaction for MELCOR, and a more gradual pressurization of the containment, leading to containment failure much later than for STCP.

\section{Environmental Releases}

A comparison of environmental releases (Madni, 1993a] showed that MELCOR calculates lower release fractions of refractories such as $\mathrm{Sr}, \mathrm{La}, \mathrm{Ce}$, and $\mathrm{Ba}$, while STCP calculates lower release fractions of volatiles such as 1 and Cs. The lower refractory releases from MELCOR occur because MELCOR calculates debris ejection into the cavity over a much longer period of time, which results in less vigorous core-concrete interactions than STCP, and hence, larger retention of the refractory fission products in the cavity.

\section{Efrect of Break Location}

There were several sensitivity calculations performed as part of the applications analyses. One of them involved comparing predicted results from simulating a LOCA sequence initiated by a 3 -inch diameter break in a hot-leg pipe and a cold-leg pipe, in the Oconee plant [Madni, 1993a].

The impact of break location on environmental release fractions was seen to be minimal for the refractory species. However, the volatile species I, Cs, Te all exhibited about an order of magnitude lower environmental release fractions, because of substantially greater retention in the RCS, for the break in a cold leg. This is expected since the pathway to the break for the fission products is via the steam generator, where substantial retention occurs. As far as timing of containment failure, for a break in a cold leg, there is greater loss of coolant out of the break. Boil-off of a larger mass of water in containment caused rapid pressurization leading to earlier containment failure. This was an example of a sensitivity calculation which caused increased confidence in the code based on "physical reasonableness" arguments. There were also cases where areas of concern emerged, as described in the next section.

\section{EVALUATION OF MELCOR IMPROVEMENTS}

As part of the applications effort, long-term station blackout analyses in Peach Bottom weré first carried out in 1990, using MELCOR 1.8BC, an interim released version between 1.8.0 and 1.8.1. In addition to the reference MELCOR calculation, several sensitivity calculations were also performed to explore the impact of varying user-input modeling and timestep control parameters on the accident progression and radionuclide releases to the environment calculated by MELCOR. The sensitivity studies helped to assess MELCOR by evaluating the changes in results in response to changes in input parameters.

An area of concern that emerged from these studies was the impact of the selection of maximum allowable timestep $\left(\Delta t_{\max }\right)$ on the calculational behavior of MELCOR. Complete sequence calculations were carried out selecting two variations of $\Delta \mathrm{t}_{\max }(5$ and $3 \mathrm{sec})$, in addition to the reference case using $\Delta t_{\max }=10 \mathrm{sec}$. Both variations were seen to delay the occurrence of most key events compared to the reference calculation and to substantially increase the release of $\mathrm{Cs}$ and 1 to the environment. The $5 \mathrm{sec}$ case gave the largest deviation in timing. With the release of a newer version of the code, $1.8 \mathrm{DN}$, the impact of $\Delta \mathrm{t}_{\max }$ was re-examined using MELCOR 1.8DNX (1.8DN with corrections for two code errors). Complete sequence calculations were carried out selecting five variations of $\Delta t_{\max }(10,5,3,2$, and $1 \mathrm{sec})$. Once again, the results showed significant differences in timing of key events, and a lack of convergence of the solution with reduction of $\Delta t_{\max }$. The maximum uncertainty in environmental release fractions was a factor of seven (for $\mathrm{Ru}$ ) and within a factor of four for the rest of the radionuclides over the entire range of $\Delta \mathrm{t}_{\max }$.

These findings were reported to the NRC, SNL, and the MELCOR Peer Review Committee. This alerted the NRC, the code developers, and the MELCOR Peer Reviewers to the importance of correcting the numerical sensitivities. As a consequence, a significant effort was undertaken to eliminate or mitigate these sensitivities. The latest released version of MELCOR, Version 1.8.2, released in April 1993, contains several new or improved models, and has corrections to mitigate numerical sensitivities [MELCOR 1.8.2, 1993]. 
Table 4. MELCOR and STCP-Predicted Timing of Key Events for LOCA (3-inch hot leg break) in Oconee

\begin{tabular}{||l|c|c||}
\hline \multicolumn{1}{|c|}{ Key Event } & \multicolumn{2}{c|}{ Time (min) } \\
\cline { 2 - 3 } & MELCOR & STCP \\
\hline Core uncovery & 15.0 & 16.0 \\
Accumulators empty & 29.9 & 21.6 \\
First gap release of fission products & 27.3 &.- \\
Start melt and relocation & 70.7 & 80.5 \\
Core collapse & 96.7 (Ring 2) & 107.1 \\
& 98.8 (Ring 1) & 124.5 \\
Lower plenum dryout & 127.4 (Ring 3) & 164.4 \\
Lower head failure & 108.3 & \\
& $113.2($ Ring 1) & \\
Start concrete attack & 123.1 (Ring 2) & 164.4 \\
Hydrogen burns begin & 133.0 (Ring 3) &.- \\
Containment failure & 120.0 & 1074.9 \\
End calculation & 162.2 & 1366.0 \\
\hline
\end{tabular}

Table 5. Impact of Maximum Allowable Timestep Size on Predicted Timing of Key Events for Station Blackout in Peach Bottom (MELCOR Version 1.8.2)

\begin{tabular}{|c|c|c|c|c|c|c|}
\hline \multirow{2}{*}{ Key Event } & & \multicolumn{5}{|c|}{ Time (sec) } \\
\hline & & $\Delta t_{\max }=10 s$ & $\Delta t_{\max }=5 s$ & $\Delta t_{\max }=3 s$ & $\Delta t_{\max }=2 s$ & $\Delta t_{\max }=1 \mathrm{~s}$ \\
\hline \multirow{3}{*}{$\begin{array}{l}\text { Gap Release of } \\
\text { Fission Products }\end{array}$} & Ring 1 & 4668.2 & 4601.4 & 4561.5 & 4527.1 & 4479.1 \\
\hline & Ring 2 & 5116.7 & 5041.4 & 5029.5 & 5007.1 & 4971.1 \\
\hline & Ring 3 & 8526.0 & 8642.1 & 8025.1 & 8378.9 & 8665.7 \\
\hline \multirow{3}{*}{ Core Collapse } & Ring 1 & $11,713.7$ & $11,537.9$ & $11,668.8$ & $11,090.1$ & $12,612.7$ \\
\hline & Ring 2 & $11,726.5$ & $11,552.7$ & $11,684.2$ & $11,117.5$ & $12,635.0$ \\
\hline & Ring 3 & $12,533.9$ & $13,685.9$ & $12,055.1$ & $12,415.4$ & $13,406.4$ \\
\hline \multicolumn{2}{|l|}{ Lower Plenum Dryout } & $11,765.5$ & $11,593.7$ & $11,716.3$ & $11,132.0$ & $12,654.5$ \\
\hline \multirow{3}{*}{$\begin{array}{l}\text { Vessel (Penetration) } \\
\text { Failure }\end{array}$} & Ring 1 & $12,244.5$ & $13,260.9$ & $13,128.6$ & $11,927.4$ & $12,778.4$ \\
\hline & Ring 2 & $11,785.9$ & $11,657.4$ & $11,758.5$ & $11,321.0$ & $12,704.0$ \\
\hline & Ring 3 & $11,785.9$ & $11,610.3$ & $11,755.5$ & $11,185.7$ & $12,676.7$ \\
\hline \multicolumn{2}{|c|}{ Reactor Vessel Depressurized } & $11,894.5$ & $11,727.1$ & $11,857.9$ & $11,286.2$ & $12,787.7$ \\
\hline \multicolumn{2}{|c|}{ Drywell Failure (Overpressure) } & $11,953.9$ & $11,925.3$ & $11,980.5$ & $11,666.2$ & $12,944.7$ \\
\hline \multicolumn{2}{|c|}{$\begin{array}{l}\text { Deflagrations Begin in Reactor } \\
\text { Building }\end{array}$} & $11,960.8$ & $11,938.3$ & $11,986.7$ & $11,676.0$ & $12,949.3$ \\
\hline \multicolumn{2}{|c|}{$\begin{array}{l}\text { Debris Ejection to Cavity } \\
\text { Begins }\end{array}$} & $15,352.8$ & $15,900.9$ & $16,032.6$ & $14,929.4$ & $15,830.4$ \\
\hline \multicolumn{2}{|l|}{ End Calculation } & $60,000.0$ & $60,000.0$ & $60,000.0$ & $60,000.0$ & $60,000.0$ \\
\hline
\end{tabular}




\section{New Timestep Sensitivities}

In order to evaluate the improved MELCOR

- version 1.8.2, the sensitivity studies to $\Delta \mathrm{t}_{\max }$ were rerun, once again selecting five variations of $\Delta t_{\max }(10,5,3$, 2 , and $1 \mathrm{sec}$ ).

Table 5 presents MELCOR-calculated timing of key events. While there is no convergence of the solution in going to a smaller $\Delta t_{\max }$, there is clearly very close agreement in the timing of key events, from gap releases of fission products, to core collapse, lower plenum dryout, vessel failure, drywell failure, onset of deflagrations in the reactor building, and debris ejection to the cavity. In most cases, the deviations in timing are limited to a few hundred seconds. Earlier calculations using MELCOR 1.8DNX showed much larger deviations, many as high as 10,000 seconds. This is certainly evidence of improved numerical behavior of MELCOR 1.8.2. There is still some residual sensitivity to threshold phenomena, and calculations using $\Delta t_{\max }=10,5$, and $2 \mathrm{sec}$ failed due to excessive $\Delta t$ reductions, the fatal errors being circumvented by using a different $\Delta t_{\max }$ for a small portion of the transient.

Activation of the new radial debris relocation model in MELCOR 1.8.2, caused (i) delayed core plate failure, (ii) a much shorter time interval between core plate and vessel failures, and (iii) penetration failures in all 3 radial rings to occur much closer together. Earlier calculations using MELCOR 1.8DNX showed staggering of penetration failures in different rings by as much as $13,000 \mathrm{sec}$.

For MELCOR-calculated environmental releases of radionuclides, again, while there is no convergence of the solution for smaller values of $\Delta t_{\max }$, the maximum deviation in release fractions is a factor of 2 , while the deviation for most of the radionuclides is much less than that [Madni, 1993f]. This is again a dramatic improvement over the earlier results using MELCOR 1.8DNX.

\section{New Debris Quench Model}

The falling debris quench model became available with the latest released version of MELCOR (1.8.2). When activated, this model allows the debris to lose heat to surrounding water in the lower plenum as it falls to the lower head, following failure of the core support plate in each radial ring.

The debris is assumed to fall with a userspecified velocity (VFALL, default value of $5 \mathrm{~m} / \mathrm{s}$ ). Heat transfer from the falling debris to the pool of water in the lower plenum is calculated using a userspecified quench heat transfer coefficient $\left(750 \mathrm{~W} / \mathrm{m}^{2}-\mathrm{K}\right.$ in all calculations reported here), and the surface area of the debris particles with user-specified particulate debris equivalent diameter of $0.01 \mathrm{~m}$. This heat transfer may or may not be sufficient to fully quench the debris before it reaches the bottom of the lower plenum, depending on the values selected for the model input parameters.

Calculations for the low pressure station blackout sequence [Madni, 1993c] showed that, when the default value for VFALL was used, the results with or without the debris quench model activated were very similar, with vessel failure always preceding lower plenum dryout. This could, perhaps, be attributed to VFALL being too high, not allowing enough time for debris to quench.

The case for a lower VFALL can be made based on the maximum velocity attainable for debris particles falling over a small height of a few meters, against the drag of water in the lower plenum. In the calculations of the previous section, to ensure that lower plenum dryout occurs prior to vessel failure, VFALL was reduced to $0.1 \mathrm{~m} / \mathrm{s}$ [Hodge, 1993] and debris particle diameter was reduced from $0.0254 \mathrm{~m}$, used in earlier Peach Bottom calculations to $0.01 \mathrm{~m}$. This parameter selection always resulted in lower plenum dryout prior to vessel failure (see Table 5).

\section{New Lower Plenum Debris Bed (BH) Model}

The $\mathrm{BH}$ model is now available to users as an option with MELCOR version 1.8.2. The BH package calculates the thermal response of the lower plenum debris, the heatup of the reactor vessel bottom head, and the release of core and structural materials from the reactor vessel to the drywell. $\mathrm{BH}$ calculations begin when the BWR lower plenum is dry, and when sufficient solid debris mass has accumulated to form the foundation of a debris bed. (Prior to these conditions being established, the original COR package models are used to determine the lower plenum debris bed/bottom head response.) Material subsequently relocated downward from the core region (solids and liquids) are added to the upper surface of the bed. Materials released from the lower plenum via penetration failures or bottom head creep rupture are transferred to the containment drywell.

The BH package was activated by (i) substituting its routines for dummy ones in MELCOR and recompiling the code to create a special BWR version of MELCOR 1.8.2, and (ii) preparing special MELGEN input for the $\mathrm{BH}$ package, starting with the sample input for LaSalle [Hodge, 1993] and modifying parameters to be consistent with the Peach Bottom input. Compared with results using the standard MELCOR lower head model, all events are slightly delayed (except for debris ejection to cavity). This delay is consistent with calculations reported by ORNL for LaSalle [Hodge, 1993]. Once again, there is early drywell failure shortly after vessel (penetration) failure. 
Vessel failure first occurs at $12,707 \mathrm{sec}$ due to penetration weld temperature exceeding DTFAIL - (temperature threshold for creep rupture of the weld). DTFAIL is calculated by the $\mathrm{BH}$ package based on two input parameters THK6 (temperature for creep rupture in $6 \mathrm{~min}, \mathrm{~K}$ ) and THK60 (temperature for creep rupture in $60 \mathrm{~min}, \mathrm{~K}$ ). Values for these parameters were selected as $1295 \mathrm{~K}$ and $1210 \mathrm{~K}$, respectively, based on suggested values in the Users' Guide (BH-UG-11) for a high pressure sequence [Hyman, 1992]. Debris ejection starts shortly thereafter. Global bottom head failure due to creep rupture occurs at $26,772.7 \mathrm{sec}$, at which time all remaining debris in the lower plenum is transferred to the drywell.

Radionuclide releases to the environment calculated using the $\mathrm{BH}$ model were significantly lower than those for the reference case using the MELCOR LH model. The results are not presented here since the interface with the Radionuclide Package in MELCOR is incomplete [Hodge, 1993].

\section{CONCLUSIONS}

MELCOR is a versatile system code, with generalized architecture, and has demonstrated robustness in simulating a variety of systems and severe accident sequences to their completion. While the documentation is indispensable, there is a general lack of sufficient guidance for selection of input parameters, nodalization, and timestep size. The code developers have begun working to provide improved user guidance.

The user must be aware that MELCOR, as any other system code, has limitations in its modeling and numerics, and there will be an uncertainty associated with its calculation of accident progression and source terms to the environment. Furthermore, typical input size for a full-plant simulation would be a few thousand lines, with many input choices. Thus, the user shoulders a heavy responsibility for the correctness and appropriateness of the input model, and hence knowledge and experience are essential.

An cvaluation of MELCOR improvement has shown that MELCOR 1.8.2 is a more robust code, with significant improvement in its numerical behavior. Based on results from the Peach Bottom station blackout analyses, the selection of the most appropriate timestep size appears to be less critical with the new code version. Several new models have been added to MELCOR 1.8.2, that have enhanced MELCOR's modeling capabilities.

The BNL program for independent assessment of MELCOR has provided feedback to SNL and the NRC on code errors/deficiencies, has contributed significantly towards improving the code, and will hopefully continue to do so in the future. Feedback was also provided to the Peer Review Committee and the NRC on "Lessons Learned" with MELCOR. Finally, MELCOR Benchmarking and Applications at BNL have provided and will continue to provide a focus on code capabilities and limitations, user tricks and workarounds to extend the capabilities of the code, and user needs, i.e., what the code requires from a user, in order to be used in a meaningful way, and also, what the user needs from MELCOR to enable him to use the code effectively.

Such efforts will be able to guide MELCOR towards maturity as a severe accident/source term analysis tool for PRA studies of current LWR plant designs, which is one of the key targeted applications for MELCOR.

\section{ACKNOWLEDGEMENT}

The authors wish to extend their appreciation to A. Costantini for her excellent preparation of this paper.

\section{REFERENCES}

BOYACK, B.E., ET AL. 1992 - MELCOR Peer Review - Los Alamos National Laboratory, LA-12240.

GIESEKE, J.A., ET AL. 1986 - Source Term Code Package: A User's Guide - NUREG/CR-4587, BMI2138, Battelle Memorial Institute.

HODGE, S.A., ET AL. 1993 - BWR-Specific Models for MELCOR - presented at the 1993 CSARP Review Meeting, Bethesda, MD.

HYMAN, C.R., SANDERS, R.L. 1992 - BH Package Users' Guide, Version 1.0.3 - Oak Ridge National Laboratory.

MADNI, I.K. 1988 - Review of Experimental Data Alternatives for Benchmarking MELCOR - Brookhaven National Laboratory Technical Report A-3281.

MADNI, I.K. 1989 - MELCOR Simulation of the PBF Severe Fuel Damage Test 1-1 - Proc. 26th National Heat Transfer Conference, Philadelphia, PA, AIChE Symp. Ser., 85, 269.

MADNI, I.K. 1990 - MELCOR Simulation of LongTerm Station Blackout at Peach Bottom - Proceedings of the 18th Water Reactor Safety Information Meeting, NUREG/CP-0113. 
MADNI, I.K. 1991 - MELCOR Lessons Learned: A User Perspective - Brookhaven National Laboratory Technical Report A-3281.

MADNI, I.K. 1991 - MELCOR Modeling of the PBF Severe Fuel Damage Test 1.4 - Proc. International Conference Probabilistic Safety Assessment and Management (PSAM), Beverly Hills, CA and Elsevier Science.

MADNI, I.K., GUO, X.D. 1991 - MELCOR Simulation of the Full-Length High-Temperature 4 Experiment Brookhaven National Laboratory Draft Technical Report A-3281.

MADNI, I.K. 1991 - Analysis of Severe Accident Scenarios in Oconee Using MELCOR - Brookhaven National Laboratory Draft Technical Report, A-3281.

MADNI, I.K., GUO, X.D. 1992 - MELCOR Modeling of the NRU Full-Length High-Temperature 2 Experiment - Nuclear Technology, Vol. 99.

MADNI, I.K. 1993 - MELCOR Analyses of Severe Accident Scenarios in Oconee, a B\&W PWR Plant Proc. Probabilistic Safety Assessment International Topical Meeting (PSA '93), Clearwater Beach, FL.

MADNI, I.K. 1993 - MELCOR Analysis of Station Blackout in Calvert Cliffs, a Combustion Engineering Plant - BNL Technical Report A-3281 (Draft, Rev. 1).

MADNI, I.K. 1993 - MELCOR 1.8.2 Analyses of InVessel Structure Temperatures and Debris Ejection Characteristics During a Low-Pressure Station Blackout in Peach Bottom - Draft Report A-3281, SRED-16, Brookhaven National Laboratory.

MADNI, I.K., GUO, X.D. 1993 - MELCOR Analysis of the NRU Full-Length High Temperature 4 Experiment - presented at the 1st MCAP Technical Meeting, Bethesda, MD.

MADNI, I.K., GUO, X.D. 1993 - MELCOR 1.8.2 Simulation of the Full-Length High-Temperature 5 Experiment - Brookhaven National Laboratory Draft Technical Report.

MADNI, I.K. 1993 - Evaluation of MELCOR Improvements: Peach Bottom Station Blackout Analyses - presented at the 21st Water Reactor Safety Information Meeting, Bethesda, MD.

MADNI, I.K. - Analysis of Long-Term Station Blackout Without ADS at Peach Bottom Using MELCOR -
NUREG/CR-5850, BNL-NUREG-52319 (to be published).

MELCOR 1.8.2 Users' Guide/Reference Manual, Sandia National Laboratories, February 1993.

OSTEK, D.J. 1987 - Results of the Four PBF Severe Fuel Damage Tests - Transactions - 15th Water Reactor Safety Information Meeting, NUREG/CP-0090.

SUMMERS, R.M., ET Al. 1991 - MELCOR 1.8.0: $A$ Computer Code for Severe Nuclear Reactor Accident Source Term and Risk Assessment Analyses NUREG/CR-5331, SAND90-0364, Sandia National Laboratories.

U.S. NUCLEAR REGULATORY COMMISSION, 1992 - Severe Accident Research Program Plan Update NUREG-1365, Rev. 1.

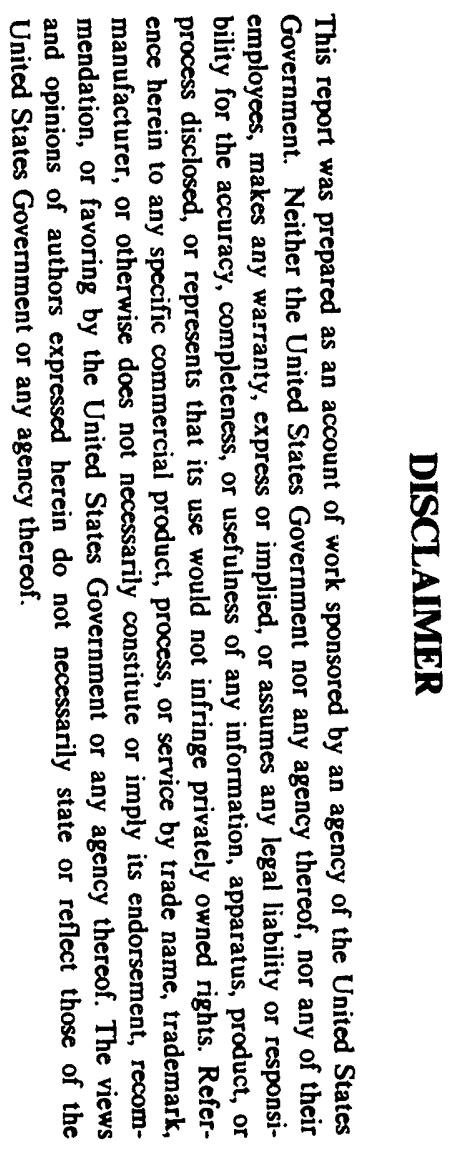

